\title{
Memory span as a measure of individual differences in memory capacity
}

\author{
MARYANNE MARTIN \\ University of Oxford, Oxford, England OX13UD
}

\begin{abstract}
Two experiments were carried out to investigate whether the immediate digit span measure traditionally used in the assessment of individual differences in cognition is a good predictor of performance on other memory tasks. In the first experiment, it was found that subjects' digit spans were not significantly related to their performances on either short-term or longterm memory tasks, or to theoretical measures of their memory store capacities. Memory for the temporal occurrence of events, however, proved to be positively correlated with digit span. A second experiment confirmed that digit span was correlated with memory for the temporal occurrence of events, but not with item memory. Thus it was concluded that an individual's digit span reflects his ability to retain information about the order of a sequence of events rather than the capacity of his short- or long-term memory.
\end{abstract}

Memory span for digits, devised by Jacobs (1887), is perhaps the most ubiquitous component in tests of intelligence (Wechsler, 1944). It forms part of the original 1905 Binet scale and all the subsequent revisions of it. It is also widely used in clinical diagnosis (see Mayer-Gross, Slater, \& Roth, 1969). Its appeal presumably lies in its simplicity and its intuitive validity as a measure of short-term memory. This idea has been supported by some recent papers in cognitive psychology that have renewed interest in the relationship between memory span and other measures of memory and cognitive processing (e.g., Baddeley, Thomson, \& Buchanan, 1975; Cavanagh, 1972). Cavanagh (1972) reported a linear relationship between scanning time and the reciprocal of memory span: for different materials, the greater the memory span the less the scanning time per item as measured in the item-recognition paradigm of Sternberg (1966). Baddeley et al. (1975) showed that memory span and reading rate for words composed of varying numbers of syllables were highly correlated. However, both these studies involved correlations over different types of material rather than over different people. Thus, the important question arises whether individual differences in memory span among people correlate with other measures of memory ability.

In the last 25 years, theorists have commonly distinguished two components of human memory: short-term memory and long-term memory. However, the term "short-term memory" has been used in connection with both a distinct mechanism or process and also any memory experiment involving short

This research was carried out when the author was in receipt of a grant from the Science Research Council. Requests for reprints should be sent to $M$. Martin, University of Oxford, Department of Experimental Psychology, South Parks Road, Oxford, England OX1 3UD. retention intervals. For clarity, the terminology of Waugh and Norman (1965) will be followed here. They reserved the above terms for the memory paradigms, and characterized two independent theoretical stores as primary memory and secondary memory, using terms introduced by James (1890). Both stores could be involved in retrieval of material after short delays, because an assumption was made of rapid transfer of information from primary to secondary memory. Recent reviews of this area can be found in Baddeley (1976) and Murdock (1974). The present paper investigates the relationship of memory span to both short- and long-term memory performance and to primary and secondary memory capacities.

Probably the most widely used experimental task for investigating short- and long-term memory is free recall. A list of unrelated words is presented, and is followed by recall of the words either immediately or after an interval that has been filled by a distractor task. Immediate free recall may be taken as the prototypical short-term memory task, and delayed free recall as the prototypical long-term memory task.

Several different measures of primary and secondary memory have been proposed (see Watkins, 1974). Four of these, reflecting different theoretical viewpoints, were calculated for the data of the present experiment. These measures are derived as follows.

\section{Waugh and Norman (1965) Method}

This method for estimating the capacity of primary memory from the U-shaped serial position curve obtained for immediate free recall is based on the assumption that the probability of Item $i$ being recalled $\left(R_{i}\right)$ is given by the following:

$$
\mathrm{R}_{\mathrm{i}}=\mathrm{PM}_{\mathrm{i}}+\mathrm{SM}_{\mathrm{i}}-\mathrm{PM}_{\mathrm{i}} \mathrm{SM}_{\mathrm{i}}
$$

where $\mathbf{P M}_{\mathrm{i}}$ and $\mathrm{SM}_{\mathrm{i}}$ represent the independent 
probabilities of Item $i$ being stored in primary and secondary memory, respectively. Equation 1 may be rearranged to obtain the formula:

$$
\mathrm{PM}_{\mathrm{i}}=\frac{\mathrm{R}_{\mathrm{i}}-\mathrm{SM}_{\mathrm{i}}}{1-\mathrm{SM}_{\mathrm{i}}}
$$

Waugh and Norman (1965) assumed that, apart from the more rehearsed first few serial positions of a list, the value of $\mathbf{S M}_{\mathbf{i}}$ is constant, and can be estimated for the terminal part of the list as the average value of $R_{i}$ over the central part of the list (this was taken as Serial Positions 4-7 in the 13-item lists of the present study). Thus, the value of $\mathrm{PM}_{\mathrm{i}}$ can be calculated from Equation 2 for each of the terminal positions of the list (in the present case, 8-13), and summed to yield an estimate of the total capacity of primary memory. The amount stored in secondary memory in the present experiment was calculated as the sum of the above asymptotic values over the terminal positions together with the total recalled in the preterminal positions.

\section{Modified Waugh and Norman Method}

Two possible sources of error arise with the Waugh and Norman (1965) method. The first is that recency items may be less well registered in secondary memory, because following delayed recall, negative recency has been observed under certain circumstances (Craik, 1970; Gardiner, Thompson, \& Maskarinec, 1974). Second, not all items presented necessarily enter primary memory. In order to take into account these possible sources of error, Watkins (1974) suggested a modified version of the Waugh and Norman (1965) method, such that Equation 1 should be modified to:

$$
R_{i}=P_{i}+S M_{i}-\frac{P M_{i} S M_{i}}{R_{f}},
$$

where $R_{f}$ is the probability of recalling the final list item, which is used as an estimate of primary memory entry probability. Thus, Equation 3 may be rewritten as:

$$
P M_{i}=\frac{R_{f}\left(R_{i}-S M_{i}\right)}{R_{f}-S M_{i}} .
$$

\section{Tulving and Patterson (1968) Method}

Tulving and Patterson (1968) interpreted recall of an item following immediate free recall as deriving from primary memory if it has been presented at one of the last four serial positions. Recall of items from all earlier positions is attributed to secondary memory.

\section{Baddeley (1970) and Raymond (1969) Method}

This method involves the use of information from a delayed free recall procedure (in which a verbal distractor task intervenes between list presentation and recall) as well as immediate free recall information. The delayed recall (mean number recalled $=\mathrm{D}$ ) is assumed to correspond to the contents of secondary memory. It may then be shown that the total content of primary memory may be calculated as $\mathrm{N}[(\mathrm{I}-\mathrm{D}) /(\mathrm{N}-\mathrm{D})]$, where $\mathrm{N}$ is the number of items in the list and $\mathrm{I}$ is the mean number recalled on an immediate test. Due to the occurrence of a primacy effect in the present study, recall from the first three serial positions was omitted from the calculations of primary and secondary memory.

A further class of models of memory postulates separate representation of item and order information (e.g., Brown, 1958; Crossman, 1961; Healy, 1974; Murdock, 1976). One method of measuring memory for the latter is to require subjects to recall the order as well as the identity of items: An item is scored correct if and only if it is recalled in the correct serial position. The first experiment was carried out to determine whether individual subjects' memory spans were related to their memory store capacities, or to their abilities to retain order information, or to both.

\section{EXPERIMENT 1}

\section{Method}

Subjects. There were 38 subjects in the experiment. They were between 18 and 30 years of age and were members of the Oxford Subject Panel.

Materials. Three sets of stimuli were prepared as follows. Immediate digit span lists were composed of the 10 numbers $0-9$. Sets of 10 lists were prepared, one of each length between 3 and 12 numbers. Lists of length 10 or less contained no repeated numbers, while longer lists contained one each. Three such sets were prepared.

Twelve free recall lists of 13 words were generated by sampling without replacement from the Kucera and Francis (1967) corpus of eight-letter words with frequencies in the categories $4-7$.

Four order recall 12-item lists of decimal digits were prepared. No digit was repeated more than once in a list.

Procedure. All lists were auditorily recorded, and presented over speakers to the subjects. Digit span was tested first, followed by free recall and then ordered recall. Recall was written in each case.

For immediate digit span, each list was preceded by the word "ready" $5 \mathrm{sec}$ before the onset of the list. This was spoken at a rate of 1 digit/sec. The assessment of digit span was by the method recommended by Woodworth and Schlosberg (1954). Three sets of digit span lists were given. Thus, if, for example, a subject correctly recalled all the lists up to and including six digits, a basal value of six was allotted. If above that value he succeeded twice with a seven-digit list, not at all with eight, once with nine, and none further, his total score was $6+3 / 3=7$, since equal credit was given for each correct recall above the basal level.

For free recall, the word "ready" was spoken 5 sec before the start of each list as a warning signal. It was followed by the words at a rate of one every 2 sec. After the presentation, there was either a visual instruction to recall or else a threefigure number was first shown for $30 \mathrm{sec}$. In the latter case, subjects had to count backward by threes as fast as possible, 
Table 1

Group Means and Standard Deviations in Experiment 1

\begin{tabular}{|c|c|c|c|c|c|c|c|c|}
\hline Measure & Mean & SD & $\begin{array}{c}\text { Estimates of } \\
\text { Primary Memory }\end{array}$ & Mean & SD & $\begin{array}{c}\text { Estimates of } \\
\text { Secondary Memory }\end{array}$ & Mean & SD \\
\hline Digit span & 7.41 & 1.26 & Waugh \& Norman (1965) & 3.21 & .74 & Waugh \& Norman (1965) & 4.20 & 1.51 \\
\hline Order recall & $48.79 \%$ & $16.09 \%$ & Modified Waugh \& Norman & 3.41 & .75 & Tulving \& Patterson (1968) & 3.21 & 1.05 \\
\hline Immediate free recall & $48.58 \%$ & $7.87 \%$ & Tulving \& Patterson (1968) & 3.11 & .38 & Baddeley (1970) & 2.65 & .85 \\
\hline Delayed free recall & $28.42 \%$ & $9.27 \%$ & Baddeley (1970) & 3.38 & .83 & & & \\
\hline
\end{tabular}

and write down the numbers they reached. A period of $2 \mathrm{~min}$ was allowed for the recall of each list.

For order recall, the word "ready" preceded each list by $5 \mathrm{sec}$. It was followed by the digits at a rate of $1 \mathrm{digit} / \mathrm{sec}$. At the end of the list, those digits that could be remembered were written in answer booklets in columns corresponding to the different serial positions of input.

\section{Results and Discussion}

The means and standard deviations of subjects' scores on the different measures are shown in Table 1. The correlation between subjects' digit spans and immediate free recall scores was not significant $[\mathrm{r}(36)=.12]$. Similarly, the correlation between digit spans and delayed free recall scores failed to reach significance $[\mathrm{r}(36)=.12]$. Thus, digit span is not a good predictor of performance on either short-term or long-term memory tasks. However, the correlation between immediate and delayed free recall was significant $[\mathrm{r}(36)=.57, \mathrm{p}<.001]$.

The correlations between digit span and the four separate estimates of primary memory also each failed to reach significance [Waugh \& Norman (1965) method: $\mathrm{r}(36)=.11$; modified Waugh \& Norman method: $r(36)=.12$; Tulving \& Patterson (1968) method: $\mathrm{r}(36)=.20$; Baddeley $(1970)$ method: $\mathrm{r}(36)=.18]$. A similar pattern of results occurred for the three estimates of the content of secondary memory [correlations with digit span for Waugh \& Norman (1965) method, original and modified: $r(36)=.00$; Tulving \& Patterson (1968) method: $r(36)=.04$; Baddeley (1970) method: $r(36)=.11]$. Thus, performance on digit span is not a good indicator of either the capacity of primary memory or the number of items that enter secondary memory in a given situation.

In contrast to the above, the correlation between digit span and order recall was highly significant $[\mathrm{r}(36)=.66, \mathrm{p}<.001]$. Hence, digit span appears to be a good indicator of memory for the order of items, but not for the retention of the items themselves.

The lack of correlation between digit span and scores on tasks involving memory for item information might, however, have resulted from the measures themselves being unreliable. This possibility was examined by calculating in each case a split-half reliability statistic, $r$, using the Spearman-Brown formula. The measures for each subject were recalculated for alternate lists (i.e., odd- or even-numbered lists) separately. Generally, the agreement between the measures derived from the two was satisfactorily high. The values of the splithalf reliability were as follows: for immediate free recall, $r=.72$; for delayed free recall, $r=.76$; for primary memory estimates using the Waugh and Norman (1965) method, $r=.76$; for primary memory estimates using the modified Waugh and Norman method, $r=.60$; using the Tulving and Patterson (1968) method, $r=.50$, using the Baddeley (1970) method, $r=.48$; for secondary memory estimates using the Waugh and Norman (1965) method, $r=.72$; using the Tulving and Patterson (1968) method, $r=.69$; using the Baddeley (1970) method, $r=.79$.

The results suggest that digit span is a good predictor of a person's ability to remember the order of a sequence, but not of the ability to remember the identity of the items in that sequence. It should be noted, however, that the present experiment did not provide a pure measure of order recall in that the subject's score in that condition represented also the subject's ability to remember the number of occurrences of each type of digit. Thus, it appears advisable to test the hypothesis further by comparing the correlation between digit span and two different measures of recall obtained from the same ordered recall test. Using a strict measure of recall, credit is given only for items assigned in recall to the correct serial position. Using a lenient measure of recall, however, instructions notwithstanding, items are scored correct irrespective of the serial position to which they are assigned by the subject. If subjects are instructed to guess when in doubt, then it is predicted from the above hypothesis that the two measures obtained from the same set of data will show different correlations with memory span. The strict measure involving memory for order should yield a higher correlation with memory span than the lenient measure requiring only item information. This prediction was tested in Experiment 2.

\section{EXPERIMENT 2}

\section{Method}

Subjects. There were 16 subjects in the experiment. They were between 18 and 30 years of age and were members of the Oxford Subject Panel.

Materials. The digit span lists that were used were the same as those of Experiment 1. Measurement of digit span was followed by that of ordered recall performance.

Order recall lists were composed of three pairs of letters selected from a set of 12 possible letters. The same letter never occurred twice in a string of three pairs, although subjects were 
not aware of this constraint. Seventy-two lists were prepared using Latin squares so that the number of occurrences of each letter in each position was balanced. A cine-film of the stimuli was shot with a Minolta XL-400 Super-8 movie camera, using a single-frame advance mechanism. The film was then played back on a Philips cassettescope, with the timing of the presentation of each frame controlled by BRD logic modules, and a videotape recording made of the cassettescope display. The word "ready" and a short toneburst preceeded each list presentation by $4 \mathrm{sec}$ to act as a warning signal. Three pairs of letters were presented at a rate of 2 pairs $/ \mathrm{sec}$. A recall interval of $30 \mathrm{sec}$ followed.

Procedure. The procedure for the auditory digit span lists was the same as in Experiment 1.

After the presentation of each list of letters for ordered recall, subjects wrote down the letters, guessing if necessary, in answer booklets in squares corresponding to the different serial positions of input. Two methods of scoring the data were employed. Using the strict criterion, an item was scored correct only when it had occurred in the previously presented list and was placed in the square corresponding to the serial position of input. Using the lenient criterion, an item was scored correct if it had occurred in the previously presented list, irrespective of its position at output.

\section{Results and Discussion}

The means and standard deviations of subjects' scores on the different measures are shown in Table 2. In accordance with the predictions, the correlation between digit span and ordered recall using the strict criterion of scoring was significant $\operatorname{l}(14)=.63$, $\mathrm{p}<.01$ ], whereas the correlation between digit span and ordered recall using the lenient criterion of scoring failed to reach significance $[\mathrm{r}(14)=.28]$. The correlation between the two methods of scoring the same data was significant $[\mathrm{r}(14)=.72, \mathrm{p}<.01]$. The lack of correlation using the lenient criterion may result from its producing an unreliable measure. This possibility was examined by calculating its splithalf reliability statistic, $r$, using the Spearman-Brown formula. The lenient criterion of scoring was recalculated for each subject using alternate lists (i.e., oddor even-numbered lists), thus providing two measures. The split-half reliability was satisfactorily high $(r=.91)$.

\section{GENERAL DISCUSSION}

The results of both experiments support the hypothesis that the digit span score is a good predictor of the ability to remember temporal sequence, but not of the ability to remember item information. However, the results reported here are in apparent conflict with those cited by Craik (1971). He reported significant correlations between word span and both primary memory $[\mathrm{r}(18)=.49]$ and secondary memory $[\mathrm{r}(18)=.72]$. A possible source of the discrepancy is the difference between digit and word span techniques. The digit span technique uses only a small set of items and thus, at least for longer lists, the subject is simply arranging known items in their correct order. In contrast, a very large set of items may be
Table 2

Group Means and Standard Deviations in Experiment 2

\begin{tabular}{lcl}
\multicolumn{1}{c}{ Measure } & Mean & SD \\
\hline Digit span & 7.10 & 1.18 \\
Order recail (strict) & $55.90 \%$ & $5.86 \%$ \\
Order recall (lenient) & $67.12 \%$ & $5.22 \%$ \\
\hline
\end{tabular}

used in the word span technique. The subject usually has little idea of what the possible set of words is, so he has to remember both item and order information. Thus, it is perhaps not surprising that the word span score, unlike the digit span score, should correlate significantly with other measures of item-information retention.

In conclusion, it appears that digit span score does not provide a general measure of performance on shortor long-term memory tasks nor of the theoretical concepts of primary and secondary memory, but rather, it depends upon the ability to remember the order in which events occur. It is suggested therefore that, for the assessment of individual differences in cognitive ability, consideration should be given to the supplementing of the traditional digit span procedure by one based upon free recall, or to its replacement by a word span procedure that assesses both order and item information.

\section{REFERENCES}

BADDELEY, A. D. Estimating the short-term component in free recall. British Journal of Psychology, 1970, 61, 13-15.

BADDELEY, A. D. The psychology of memory. New York: Harper \& Row, 1976.

Baddeley, A. D., Thomson, N., \& Buchanan, M. Word length and the structure of short-term memory. Journal of Verbal Learning and Verbal Behavior, 1975, 14, 575-589.

Brown, J. Some tests of the decay theory of immediate memory. Quarterly Journal of Experimental Psychology, 1958, $10,12-21$

Cavanagh, J. P. Relation between the immediate memory span and the memory search rate. Psychological Review, $1972,79,525-530$.

CRAIK, F. I. M. The fate of primary memory items in free recall. Journal of Verbal Learning and Verbal Behavior, $1970,9,143-148$.

CRALK, F. I. M. Primary memory. British Medical Bulletin, 1971, 27, 232-236.

Crossman, E. R. F. W. Information and serial order in human immediate memory. In C. Cherry (Ed.), Information theory. London: Butterworths, 1961.

Gardiner. J. M., Thompson, C. P., \& Maskarinec, A. S. Negative recency in initial free recall. Journal of Experimental Psychology, 1974, 103, 71-78.

HeAly, A. F. Separating item from order information in short-term memory. Journal of Verbal Learning and Verbal Behavior, 1974, 13, 644-655.

JACOBS, J. Experiments on "prehension." Mind, 1887, 12, 75-79.

JAMEs, W. Principles of psychology. New York: Holt, 1890.

Kućera, H., \& Francis, W. N. Computational analysis of present day American English. Providence, R.I: Brown University Press, 1967. 
Mayer-Gross, W., Stater, E., \& Roth, M. Clinical psychiatry (3rd ed. revised by E. Slater \& M. Roth). London: Bouilliere, Tindall, \& Cassell, 1969.

Murdock, B. B., JR. Human memory: Theory and data. Potomac, Md: Erlbaum, 1974.

Murdock, B. B., $J_{R}$. Item and order information in shortterm serial memory. Joumal of Experimental Psychology: General, 1976, 105, 191-216.

RAYMOND, B. Short-term storage and long-term storage in free recall. Journal of Verbal Learning and Verbal Behavior, $1969,8,567-584$.

SternaERG, S. High-speed scanning in human memory. Science, 1966, 153, 652-654.

Tulving. E., \& Patterson, R. D. Functional units and retrieval processes in free recall. Journal of Experimental Psychology, 1968, 77, 239-248.

WatKINS, M. J. Concept and measurement of primary memory. Psychological Bulletin, 1974, 81, 695-711.

Waugh, N. C., \& Norman, D. A. Primary memory. Psychological Review, 1965, 72, 89-104.

WECHSLER, D. The measurement of adult intelligence. Baltimore: Williams \& Watkins, 1944.

WoODworth, R. S., \& SchlosBerg, H. Experimental psychology. London: Methuen, 1954.

(Received for publication June 16, 1977; accepted November 7, 1977.) 